Article

\title{
Evaluation of the Antinociceptive Activity and Acute Oral Toxicity of Standardized Ethanolic Extract of the Rhizome of Curcuma xanthorrhiza Roxb
}

\author{
Sutha Devaraj ${ }^{1}$, Azadeh Sabetghadam Esfahani ${ }^{1}$, Sabariah Ismail ${ }^{1, *}$, Surash Ramanathan ${ }^{1}$ \\ and Mun Fei Yam ${ }^{2}$ \\ 1 Centre for Drug Research, Universiti Sains Malaysia, 11800, Pulau Pinang, Malaysia \\ 2 School of Pharmaceutical Sciences, Universiti Sains Malaysia, 11800, Pulau Pinang, Malaysia \\ * Author to whom correspondence should be addressed; E-Mail: sabaris@usm.my.
}

Received: 16 January 2010; in revised form: 25 February 2010 / Accepted: 22 March 2010 /

Published: 22 April 2010

\begin{abstract}
Ethanolic extract of Curcuma xanthorrhiza was used to evaluate the analgesic and toxicity effects in vivo. The extract was standardized using GC-MS, which showed that $1 \mathrm{mg}$ of Curcuma xanthorrhiza ethanolic extract contains $0.1238 \mathrm{mg}$ of xanthorrhizol. The analgesic activity was studied in rats using three different models, namely the hot plate test, tail flick test and formalin-induced pain test. The acute oral toxicity was examined by the oral administration of standardized Curcuma xanthorrhiza ethanolic extract in mice at doses ranging from $300-5,000 \mathrm{mg} / \mathrm{kg}$ and observation for 14 days. Standardized Curcuma xanthorrhiza ethanolic extract did not show significant analgesic effect in the hot plate and tail flick tests. However, in the formalin-induced pain test, Curcuma xanthorrhiza ethanolic extract significantly $(\mathrm{P}<0.05)$ suppressed the paw licking time of rats in both early and late phases at doses 200 and $400 \mathrm{mg} / \mathrm{kg}$ of the extract, respectively. In the acute oral toxicity study, Curcuma xanthorrhiza ethanolic extract did not show any toxic effects in mice at $5 \mathrm{~g} / \mathrm{kg}$. These experimental results suggest that the standardized Curcuma xanthorrhiza ethanolic extract showed peripheral and central antinociceptive activity associated with neurogenic pain as well as a relative absence of toxic effects which could compromise the medicinal use of this plant in folk medicine.
\end{abstract}

Keywords: analgesic; acute oral toxicity; Curcuma xanthorrhiza; peripheral; standardized 


\section{Introduction}

Curcuma xanthorrhiza Roxb. is a member of the ginger family (Zingiberaceae) and a native Indonesian plant. It is grown in Thailand, Philippines, Sri Lanka and Malaysia. It is commonly known in Malaysia as 'Temu Lawak' [1]. Curcuma xanthorrhiza is a low growing plant with a root (rhizome) which is similar to ginger, with an aromatic, pungent odor and bitter taste. In traditional medicine Curcuma xanthorrhiza is reported to be useful for the treatment of hepatitis, liver complaints, diabetes, rheumatism, anticancer, hypertension and heart disorders. Curcuma xanthorrhiza has also shown antidiuretic, anti-inflammatory, anti-oxidant, anti-hypertensive, anti-rheumatic, anti-hepatotoxic, antidysmenorrheal, anti-spasmodic, anti-leucorrhoea, anti-bacterial and antifungal effects [1]. It reduces cholesterol, treats constipation, migraines and increases flow of milk during breast feeding. The Curcuma xanthorrhiza aqueous extract revealed significant hepatoprotective activity against $\beta$-Dgalactosamine induced liver damage [2]. Ozaki has reported on the anti-inflammatory activity of the Curcuma xanthorrhiza methanolic extract [3].

The traditional benefits of Curcuma xanthorrhiza were further supported by the isolation and identification of several active chemical constituents, including xanthorrhizol, curcumin and few volatile substances. Xanthorrhizol, the major component of the essential oil of Curcuma xanthorrhiza, is a bisabolane-type sesquiterpenoid. This compound makes up nearly $46.3 \%$ of the total components of the essential oil obtained through hydrodistillation [4]. Xanthorrhizol was investigated for its antibacterial [5] and anticandidal activity [6]. Lim et al, [7] have reported on the anti-inflammatory effects of xanthorrhizol against neuronal cells. Curcumin belongs to the phenol group and comprises almost 1 to $2 \%$ in ethyl acetate fraction of Curcuma xanthorrhiza. It is the second essential active compound found in this plant [8]. Curcumin has been shown to have a powerful anti-inflammatory action since it inhibits the mechanisms of arachidonic acid and leukotrine formation [1]. Curcuma xanthorrhiza contains various active volatile substances and borneol, which are present in much lower quantities [9]. Curcuma xanthorrhiza methanolic extract has shown significant antidiuretic activity [10]. Nevertheless, analgesic and toxicity studies on this plant are very limited and most work was undertaken using Curcuma xanthorrhiza methanolic and aqueous extracts [3,10]. Moreover, to date, no work has been done using ethanolic extract preparation for analgesic and toxicity screening in animals. Therefore, this study aims to investigate the acute oral toxicity and antinociceptive activity of the rhizome of Curcuma xanthorrhiza ethanolic extracts using the hot plate, tail flick and formalin tests on animal models.

\section{Results and Discussion}

\subsection{Standardization of Curcuma xanthorrhiza ethanolic extract}

GC-MS analysis of Curcuma xanthorrhiza ethanolic extract yielded a linear calibration curve for the standard compound, xanthorrhizol, which is the main compound found in this plant. The correlation coefficient was 0.998 for the respective standard curve. Xanthorrhizol was identified and quantified at 9.58 min retention time and in the Curcuma xanthorrhiza ethanolic extract as shown in Figure 1. The results revealed that $1 \mathrm{mg}$ of Curcuma xanthorrhiza ethanolic extract contains $0.1238 \mathrm{mg}$ of xanthorrhizol. 
Figure 1. Typical chromatograms from GC-MS analysis of (a) xanthorrhizol and (b) Curcuma xanthorrhiza ethanolic extract. Insets: (a) mass spectrum and chemical structure of xanthorrizol; (b) mass spectrum of Curcuma xanthorrhiza ethanolic extract with a peak at $9.58 \mathrm{~min}$; Chromatographic conditions: HP-5MS capillary column $(30 \mathrm{~m} \times 0.25 \mathrm{~mm} \times 0.25 \mu \mathrm{m})$; Injector temperature: $280{ }^{\circ} \mathrm{C}$; Oven temperature: $70{ }^{\circ} \mathrm{C}-250{ }^{\circ} \mathrm{C}$; Injection volume: $1 \mu \mathrm{L}$; Flow rate: $0.5 \mathrm{~mL} / \mathrm{min}$. Electron impact (EI): $70 \mathrm{eV}$.

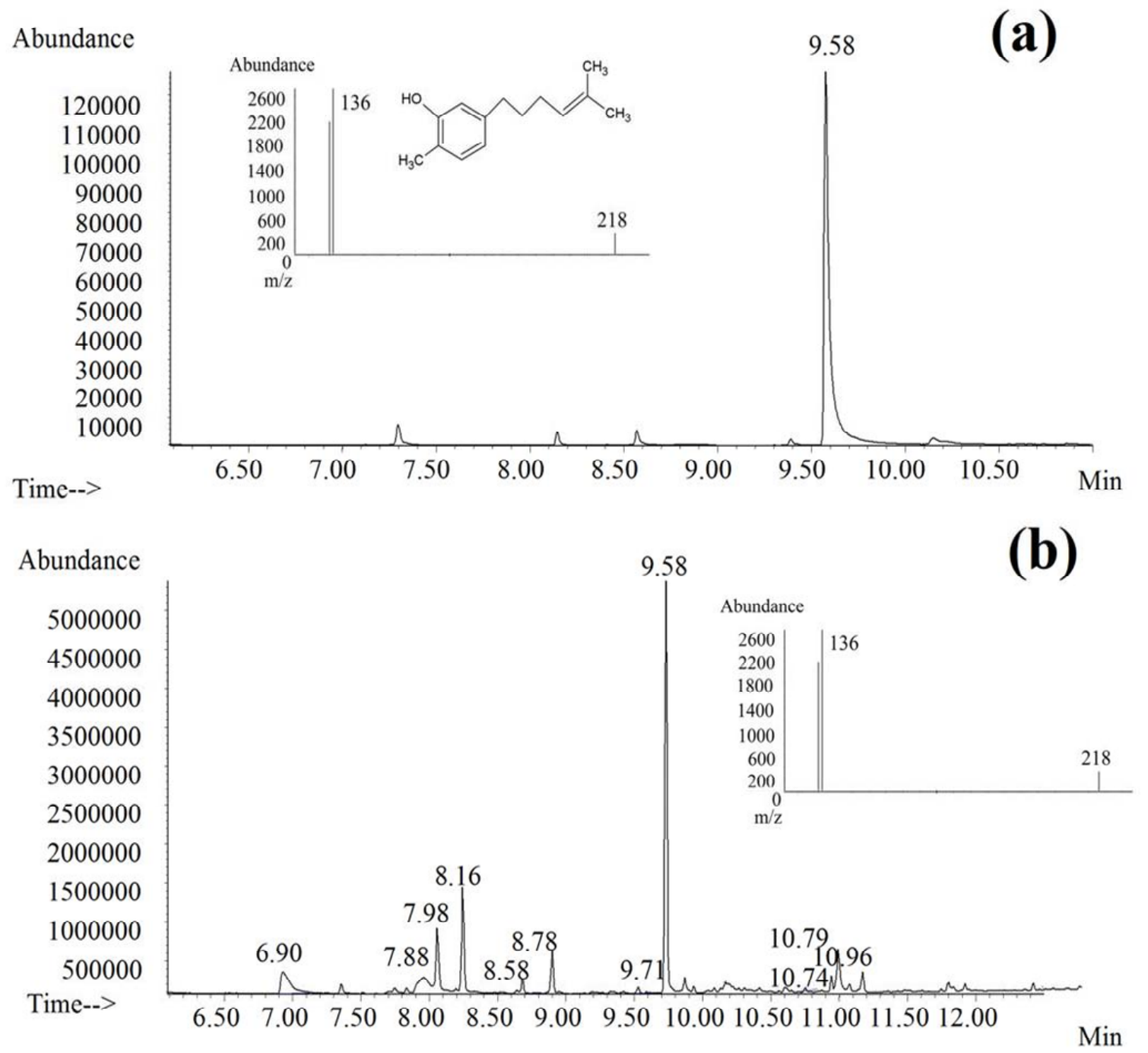

\subsection{Phytochemical screening}

The qualitative phytochemical screening tests of standardized Curcuma xanthorrhiza ethanolic extract revealed that the extract contains reducing sugars, saponins, anthraquinones, flavonoids, terpenoids and cardiac glycosides. Alkaloid, steroid, tannins and phlobatannins were absent in the Curcuma xanthorrhiza ethanolic extract, as summarized in Table 1. 
Table 1. Phytochemical profile of standardized ethanolic extract of Curcuma xanthorrhiza rhizome.

\begin{tabular}{|l|l|l|}
\hline Chemical constituents & Tests/Reagents & Results \\
\hline Reducing sugars & Fehling's reagent & ++ \\
Saponins & Frothing test & + \\
Alkaloids & Dragendroff's reagent & - \\
Flavonoids & Acid-alcohol & ++ \\
Cardiac Glycosides & Keller-Killiani test & +++ \\
Steroids & Acetic anhydride & - \\
Terpenoids & Sulphuric acid reagent & +++ \\
Tannins & Ferric chloride reagent & - \\
Phlobatannin & Hydrochloric acid & - \\
Anthraquinones & Borntrager's test & ++ \\
\hline
\end{tabular}

Key: $+++=$ abundance; $++=$ moderately present $+=$ present $\pm=$ weakly present; $-=$ absent .

\subsection{Acute oral toxicity study}

Oral administration of standardized Curcuma xanthorrhiza ethanolic extract showed no mortality in mice at doses up to $5 \mathrm{~g} / \mathrm{kg}$. There were no toxicity signs observed on the skin, fur or eyes of the animals. No noticeable behavioural changes in salivation, sleeping pattern, diarrhea or lethargy were spotted in the treated animals. This result indicates that the Curcuma xanthorrhiza ethanolic extract is non-toxic, and safe at $300 \mathrm{mg} / \mathrm{kg}, 2,000 \mathrm{mg} / \mathrm{kg}$ and 5,000 mg/kg. This explains the rational usage of this extract in folk medicine practices.

\subsection{Hot plate and tail flick tests}

The mean latency time of the analgesic effect of standardized Curcuma xanthorrhiza on the thermal pain stimuli is summarized in Tables 2 and 3.

Table 2. The effects of standardized ethanolic extract of Curcuma xanthorrhiza (CX) rhizome in the hot plate test.

\begin{tabular}{|c|c|c|c|c|c|}
\hline \multirow{2}{*}{ Groups (Dose) } & \multicolumn{5}{|c|}{ Latency of nociceptive response (s) $(n=5)$} \\
\hline & $\mathbf{0}$ & 15 & 30 & 45 & (min) \\
\hline Control & $7.05 \pm 0.70$ & $7.44 \pm 0.25$ & $8.36 \pm 1.01$ & $8.41 \pm 1.25$ & $10.32 \pm 2.16$ \\
\hline CX (100 mg/kg) & $8.82 \pm 0.70$ & $8.34 \pm 1.62$ & $11.95 \pm 1.63$ & $13.60 \pm 1.71$ & $13.86 \pm 0.14$ \\
\hline CX (200 mg/kg) & $8.82 \pm 0.70$ & $10.92 \pm 0.80$ & $13.86 \pm 2.61$ & $13.28 \pm 1.85$ & $13.93 \pm 0.86$ \\
\hline CX (400 mg/kg) & $9.44 \pm 0.96$ & $15.59 \pm 2.48$ & $12.72 \pm 2.48$ & $14.44 \pm 2.99$ & $12.52 \pm 2.26$ \\
\hline Aspirin $(300 \mathrm{mg} / \mathrm{kg})$ & $8.97 \pm 0.89$ & $16.27 \pm 2.49$ & $16.85 \pm 3.85$ & $14.80 \pm 3.39$ & $16.17 \pm 5.61$ \\
\hline Morphine $(5 \mathrm{mg} / \mathrm{kg})$ & $18.03 \pm 0.55^{*}$ & $22.08 \pm 0.65^{*}$ & $22.74 \pm 0.76^{*}$ & $10.72 \pm 1.67^{*}$ & $8.78 \pm 0.92$ \\
\hline
\end{tabular}

Data are Mean $\pm \mathrm{SEM} ; * \mathrm{p}<0.05$, evaluated by one-way analysis of variance (ANOVA) against control group. 
Table 3. The effects of standardized ethanolic extract of Curcuma xanthorrhiza (CX) rhizome in tail flick test.

\begin{tabular}{|c|c|c|c|c|c|}
\hline \multirow{2}{*}{ Groups (Dose) } & \multicolumn{5}{|c|}{ Latency of nociceptive response (s) $(n=5)$} \\
\hline & $\mathbf{0}$ & 15 & 30 & 45 & (min) \\
\hline Control & $3.16 \pm 0.20$ & $4.19 \pm 0.40$ & $3.16 \pm 0.21$ & $3.92 \pm 0.34$ & $4.71 \pm 0.85$ \\
\hline CX (100 mg/kg) & $2.40 \pm 0.39$ & $2.56 \pm 0.43$ & $2.63 \pm 0.35$ & $3.36 \pm 0.26$ & $3.80 \pm 0.82$ \\
\hline CX (200 mg/kg) & $3.34 \pm 0.34$ & $3.44 \pm 0.62$ & $2.69 \pm 0.30$ & $3.50 \pm 0.36$ & $3.03 \pm 0.43$ \\
\hline CX (400 mg/kg) & $3.14 \pm 0.62$ & $3.23 \pm 0.42$ & $3.12 \pm 0.43$ & $3.38 \pm 0.44$ & $3.95 \pm 0.17$ \\
\hline Aspirin(300 mg/kg) & $2.92 \pm 0.20$ & $2.52 \pm 0.21$ & $3.42 \pm 0.32$ & $3.37 \pm 0.35$ & $4.21 \pm 0.46$ \\
\hline Morphine ( $5 \mathrm{mg} / \mathrm{kg})$ & $10.00 \pm 0.00 *$ & $8.65 \pm 0.89 *$ & $8.63 \pm 0.78 *$ & $7.09 \pm 1.23$ & $7.19 \pm 1.28$ \\
\hline
\end{tabular}

Data are Mean $\pm \mathrm{SEM} ;{ }^{*} \mathrm{p}<0.05$, evaluated by one-way analysis of variance (ANOVA) against control group.

The ethanolic extract of Curcuma xanthorrhiza did not show significant antinociceptive effects on pain induced by hot plate and tail flick in rats compared to the control at any of the tested doses (100, 200 and $400 \mathrm{mg} / \mathrm{kg}$ ). The hot plate test involves the supraspinal nociceptive system [11], whereas the tail flick nociceptive response is transferred through the spinal dorsal horn in the central analgesic system [12]. In contrast, morphine exerted a significant increase $(p<0.05)$ in the response time in the hot plate and tail flick experiments, respectively, since it is a centrally acting narcotic drug [13]. On contrary, in this experiment, aspirin is inactive since it is a peripherally acting non-steroidal antiinflammatory drug (NSAID) [14].

\subsection{Formalin induced pain test}

The formalin test is a pain model which assesses the way an animal responds to continuous pain generated by injured tissue [15]. The formalin test has a distinctive biphasic peripheral nociceptive response termed as the early and late phases. The early phase or tonic pain response corresponds to the neurogenic phase which is directly stimulated in the paw with the release of substance P. The late phase refers to the inflammation pain response involving the release of histamine, serotonin, bradykinin and prostaglandin [16]. The standardized ethanolic extract of Curcuma xanthorrhiza has revealed significant $(\mathrm{p}<0.05)$ analgesic effects on formalin induced pain in both early $(0-5 \mathrm{~min})$ and late phases (15-30 min), as shown in Figure 2. The treated groups at 200 and $400 \mathrm{mg} / \mathrm{kg}$ showed significant reduction in the licking of paw in the early phase (neurogenic pain) and late phase (inflammatory pain) respectively. Aspirin as a peripheral analgesic significantly reduced the licking of paws in both phases compared to the control. In this study, standardized Curcuma xanthorrhiza ethanolic extract reduced the neurogenic pain (early phase) caused by formalin. As it was previously reported, some neuropathic pains can be caused by central neurogenic mechanism due to the ascending nociceptive pathway such as spinothalamic tract (STT) [17]. In contrast, thermal pain in hot plate and tail flick tests is mediated by supraspinal and spinal nociceptive pathways respectively, which are dissimilar to the neurogenic mechanism [11, 12]. Further, xanthorrhizol in Curcuma xanthorrhiza ethanolic extract has been reported to possess anti-inflammatory effect based on the previous study by 
Lim et al [7]. This suggests that the presence of xanthorrhizol in the standardized ethanolic extract of Curcuma xanthorrhiza may partly contribute to the anti-inflammatory effects observed in the late phase of formalin test.

Figure 2. Effects of the standardized ethanolic extracts of Curcuma xanthorrhiza and aspirin $(100 \mathrm{mg} / \mathrm{kg})$ on formalin induced pain in rats $30 \mathrm{~min}$ before subplantar injection of $2.5 \%$ formalin $(0.05 \mathrm{~mL})$ on the hindpaw of rats. 100,200 and $400 \mathrm{mg} / \mathrm{kg}$ represent the dose of Curcuma xanthorrhiza. Data are mean \pm SEM values for the paw licking time measured in early phase $(0-5 \mathrm{~min})$ and late phase $(15-30 \mathrm{~min}) .{ }^{*} \mathrm{p}<0.05$ compared to the control group, treated with cosolvent (ANOVA, Dunnett's test).

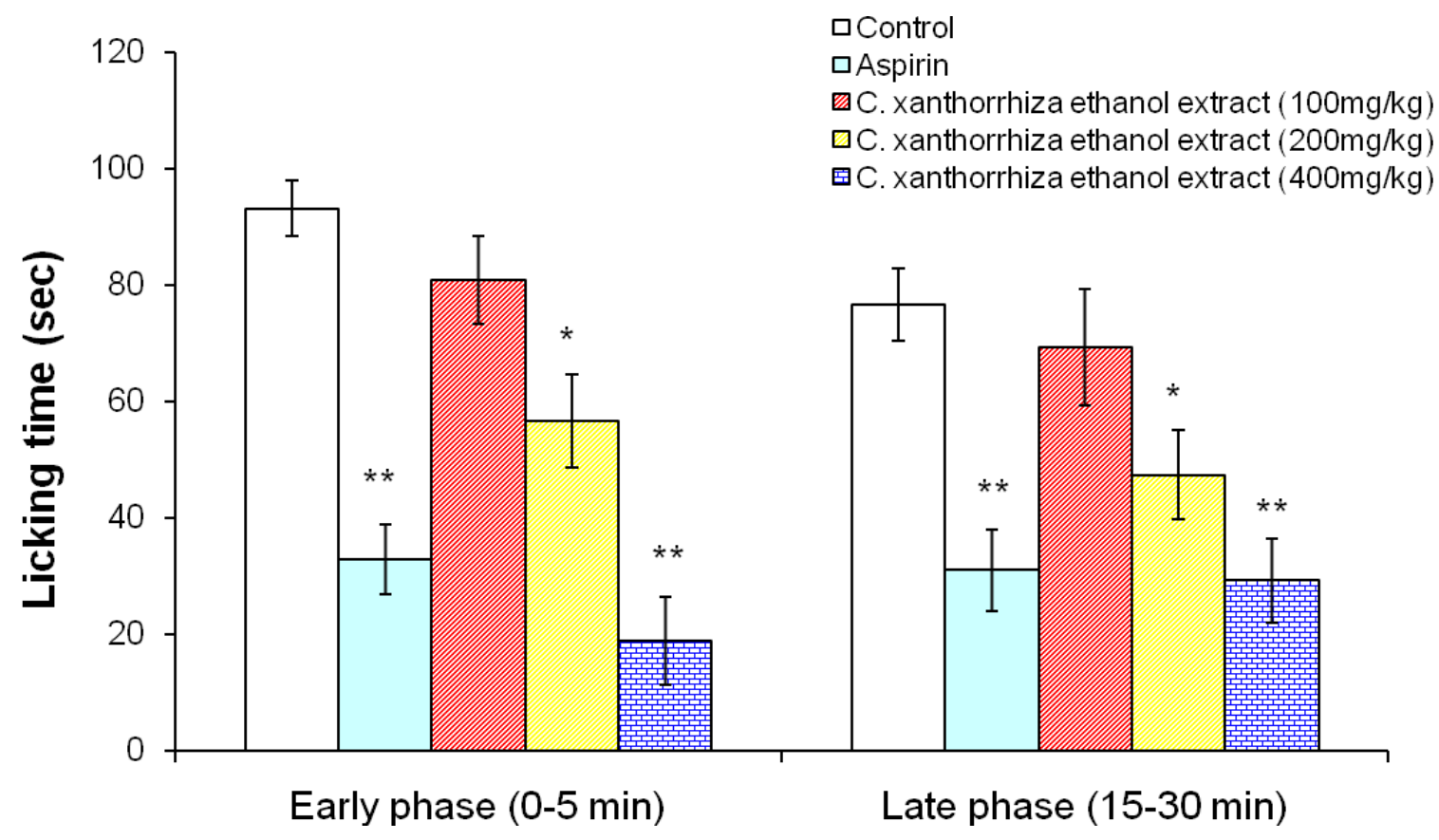

\section{Experimental}

\subsection{Materials}

All chemicals and standards were obtained from Sigma Aldrich, USA. Xanthorrhizol (standard) was purchased from Alexis, USA. Aspirin $(300 \mathrm{mg} / \mathrm{kg})$ and morphine $(5 \mathrm{mg} / \mathrm{kg})$ were prepared by dissolving in saline solution $(0.9 \% \mathrm{NaCl})$. Formalin $(2.5 \%)$ was diluted with distilled water. The extract was suspended in cosolvent solution of propylene glycol -Tween 80-distilled water (4:1:4) and referred as vehicle at the time of the oral administration for doses at 100, 200 and $400 \mathrm{mg} / \mathrm{kg}$ body weight.

\subsection{Plant material identification}

Curcuma xanthorrhiza plants were obtained from the Johor Plantation, Malaysia. A voucher specimen (11022) was authenticated and deposited at the Herbarium Unit of the School of Biological Sciences, Universiti Sains Malaysia. 


\subsection{Preparation of the extracts}

The rhizome portion of Curcuma xanthorrhiza was purchased in powder form from Chemical Engineering Pilot Plant (CEPP), UTM, Skudai, Johor, Malaysia. The coarsely powdered material (800 g) was macerated with absolute ethanol $(8 \mathrm{~L})$ for $72 \mathrm{~h}$ with occasional shaking. The maceration was repeated thrice. The extract was filtered and concentrated at reduced pressure on rotary evaporator resulting in dark yellow colored semisolid mass (yield 5.2\%).

\subsection{Animals}

Male Sprague-Dawley rats (130-180 g) and female ICR mice (20-25 g) were obtained from the Animal House, Universiti Sains Malaysia. The animals were acclimatized to laboratory conditions for seven days prior to the experiments. Five rats were housed per polycarbonate cage, with free access to food (normal laboratory chow, Gold Coin) and tap water ad libitum. The animals were maintained at room temperature under a light/dark cycle of $12 \mathrm{~h}$. All experiments were performed between 9.00 a.m. to 2.00 p.m. in order to prevent any confrontation with circadian rhythm. Experimental protocols and procedures employed in this study were approved by the Animal Ethics Committee of the Universiti Sains Malaysia with the reference number USM/PPSF/50(072) Jld 2.

\subsection{Standardization of Curcuma xanthorrhiza ethanolic extract}

The xanthorrhizol amount in the ethanolic extract of Curcuma xanthorrhiza was determined using a gas chromatography mass-spectrometry (GC/MS) system which consisted of an Agilent 6890 gas chromatograph (column) coupled with an Agilent 5973 mass spectrometry. Separation was performed with HP-5MS capillary column $(30 \mathrm{~m} \times 0.25 \mathrm{~mm} \times 0.25 \mu \mathrm{m})$. The injector was set at $280^{\circ} \mathrm{C}$ and GC was performed in the splitless mode with 1 min splitless time. The oven temperature was initiated at $70{ }^{\circ} \mathrm{C}$ for $2 \mathrm{~min}$ and increased to $250{ }^{\circ} \mathrm{C}$, held for $11 \mathrm{~min}$ at $20^{\circ} \mathrm{C} \mathrm{ramp} / \mathrm{min}$. The flow rate of the carrier gas (helium) was maintained at $0.5 \mathrm{~mL} / \mathrm{min}$. The septum purge was set at $1 \mathrm{~mL} / \mathrm{min}$. The mass spectrometer was operated with ionization in the electron impact (EI) mode using $70 \mathrm{eV}$ (ionization energy). Standard xanthorrhizol was injected at concentrations ranging from $1-50 \mu \mathrm{g} / \mathrm{mL}$ for a calibration curve. The volume of Curcuma xanthorrhiza ethanolic extract injected was $1 \mu \mathrm{g}$ ( $3 \mathrm{mg}$ of extract in $1 \mathrm{~mL}$ of absolute ethanol). Quantification was done in the single-ion monitoring (SIM) mode. Identifications were made by comparison with the NIST library GC-MS system and by their retention indexes.

\subsection{Phytochemical screening}

Phytochemical screening of the standardized Curcuma xanthorrhiza ethanolic extract was performed according to the procedures described by Sofowora [18], Harborne [19] and Siddique and Ali [20]. This experiment was carried out to detect the presence of distinct constituents such as reducing sugars, saponins, alkaloids, flavonoids, tannins, steroids, terpenoids, cardiac glycosides and anthraquinones. 


\subsection{Acute toxicity test}

Mice were divided into control and test groups $(n=5)$. The test groups received a single oral dose of standardized Curcuma xanthorrhiza ethanolic extract at $300 \mathrm{mg} / \mathrm{kg}, 2000 \mathrm{mg} / \mathrm{kg}$ and $5000 \mathrm{mg} / \mathrm{kg}$ respectively. After treatment, mice were observed for $30 \mathrm{~min}$ and thereafter for 14 days in order to notice any signs of toxicity, mortality or behavioral changes [21].

\subsection{Antinociceptive activity}

\subsubsection{Hot plate test}

The hot plate test was conducted in accordance to the method described by Woolfe and MacDonald [11] with slight modifications. The hot plate test was assessed by the Incremental Hot plate (IITC Life Sciences). The hot plate temperature was maintained at $55 \pm 1{ }^{\circ} \mathrm{C}$. Prior to treatment, only rats that showed response within $18 \mathrm{sec}$ were selected for this study. Rats (five per group) were administered with the standardized Curcuma xanthorrhiza ethanolic extract [100, 200 and $400 \mathrm{mg} / \mathrm{kg}$, per oral (p.o)], aspirin (300 mg/kg, p.o), morphine [5 mg/kg, subcutaneous (s.c)] and vehicle (cosolvent) respectively. Latency time of animal's response to heat induced pain such as licking of paw or jumping was measured for every $15 \mathrm{~min}$ over a $60 \mathrm{~min}$ period. Observation started after $30 \mathrm{~min}$ of administration of the test substances except for morphine which was $15 \mathrm{~min}$ after administration. The cut-off time was set as $45 \mathrm{~s}$ to prevent tissue damage.

\subsubsection{Tail flick test}

The tail flick was assessed by the analgesiometer (IITC Life Sciences) and using the procedures as stated by D'Amour and Smith [12] with some modifications. Rat's response to this focused heat stimulus for example flicking or removing their inflicted tail was referred as latency time (s). Prior to treatment, a sensitivity test was conducted and rats that did not attempt to withdraw tail within $4 \mathrm{sec}$ were discarded. The selected rats were allotted into control and test groups $(n=5)$. Similar dose regimens were provided as described in hot plate test. The cut-off time was fixed as $10 \mathrm{~s}$. After $30 \mathrm{~min}$ administration of the test substances and $15 \mathrm{~min}$ for morphine, the latency time was measured for every $15 \mathrm{~min}$ intervals for $1 \mathrm{~h}$.

\subsubsection{Formalin test}

The method employed was slightly amended to that described previously by Dobuisson et al. [15]. Pain was induced by injecting $0.05 \mathrm{~mL}$ of formalin $(2.5 \%)$ subcutaneously in the sub plantar of the right hind paw of the rats. Rats (five per group) received standardized Curcuma xanthorrhiza ethanolic extract (100, 200 and $400 \mathrm{mg} / \mathrm{kg}$, p.o), aspirin (100 mg/kg) and vehicle (cosolvent, p.o) $30 \mathrm{~min}$ prior to the formalin injection. These rats were placed in separate cages for the observation. The time (s) spent for licking of the injected paw was considered as indicative of pain. Nociceptive responses were measured for first $5 \mathrm{~min}$ (early phase) and 15-30 min (late phase) after formalin injection. 


\subsection{Statistical analysis}

The statistical analysis was performed by one-way ANOVA followed by Dunnett's multiple comparison tests in SigmaStat ${ }^{\circledR}$ version 3.5 Software. The results were expressed as mean \pm S.E.M to show differences in groups. The differences are considered significant when $\mathrm{P}<0.05$.

\section{Conclusions}

The experimental evidence acquired in this study implied that standardized ethanolic extract of Curcuma xanthorrhiza is non-toxic and possesses peripheral antinociceptive effects by blocking the inflammation pain response. The standardized ethanolic extract of Curcuma xanthorrhiza also exhibited a central antinociceptive effect which is associated with the neurogenic pathway and not the opioid pathway. Xanthorrhizol, one of the major constituent quantified in this extract, may contribute to the respective antinociceptive effects. However, further investigation is required to conclusively prove antinociceptive activity on the bioactive compound/s.

\section{Acknowledgements}

This project was funded by Universiti Sains Malaysia Research University (RU) grant. The authors are grateful to Jayant Indurkar from Centre for Drug Research, Universiti Sains Malaysia for proof reading assistance. Sutha Devaraj and Azadeh Sabetghadam were supported by USM fellowship from Institute of Postgraduate Studies, Universiti Sains Malaysia.

\section{References}

1. Sears, B. The Anti-Inflammation Zone-Reversing the Silent Epidemic That's Destroying Our Health; Harper Collins Publishers: New York, NY, USA, 2005; pp. 75-87.

2. Song, C.L.; Chao, W.T.; Chun, C.L.; Yun, H.L.; Supriyatna, S. Protective and Therapeutic Effect of the Indonesian Medicinal Herb Curcuma xanthorrhiza on P-D-Galactosamine-induced Liver Damage. Phytother. Res. 1996, 10, 131-135.

3. Ozaki, Y. Anti-inflammatory effect of Curcuma xanthorrhiza. Roxb and its active principles. Chem. Pharm. Bull. 1990, 38, 1045-1048.

4. Yew, H.C.; Fariza, J.N.; Rozie, S.; Thiam, T.T.; Hawariah, L.P.A.; Hasnah, M.S.; Badrul, A.A.R.; Noor, R.A.; Zakiah, I. Combined xanthorrhizol-curcumin exhibits synergistic growth inhibitory activity via apoptosis induction in human breast cancer cells MDA-MB-231.Cancer Cell Int. 2009, 9, 1 .

5. Hwang, J.K.; Shim, J.S.; Pyun, Y.R. Antibacterial activity of xanthorrhizol from Curcuma xanthorrhiza against oral pathogens. Fitoterapia 2000, 71, 321-323.

6. Yaya, R.; Dongeun, Y.; Hwang, J.K. In vitro anticandidal activity of xanthorrhizol isolated from Curcuma xanthorrhiza Roxb. J. Antimicrob.Chemother. 2006, 57, 1231-1234.

7. Lim, C.S.; Jin, D.Q.; Mok, H.; Oh, S.J.; Lee, J.U.; Hwang, J.K.; Ha, I.; Han, J.S. Antioxidant and anti-inflammatory activities of xanthorrhizol in hippocampal neurons and primary cultured microglia. J. Neurosci. Res. 2005, 82, 831-838. 
8. Sharin, R.; Abas, F.; Khozirah, S.Characterization of the components present in the active fractions of health gingers (Curcuma xanthorrhiza and Zinger zerumbet) by HPLC-DAD ESIMS. Food Chem. 2007,104, 1183-1191.

9. Simon, M.; Cherry, B. Principles and Practice of Phytotherapy. Modern Herbal Medicine; Churchill Livingstone Publishers: New York, NY, USA, 2006; pp. 569-578.

10. Mahmood, M.K.; Sitesh, C.B.; Saiful, I.; Mohammad, S.A. Analgesic and antidiuretic of Curcuma xanthorrhiza. J. Pharm. Sci. 2004, 3, 1-2.

11. Woolfe G.; Macdonald, A.D. The evaluation of the analgesic action of pethidine hydrochloride (demerol). J. Pharmacol. Exp. Ther. 1944, 80, 300-307.

12. D'Amour, E.E.; Smith, D.L. A method of determining loss of pain sensation. J. Pharmacol. Exp. Ther. 1941, 72, 74-79.

13. William, L.D.; Louis, S.H. Antinociceptive activity of the narcotic antagonist analgesics and antagonistic activity of narcotic analgesics in rodents. J. Pharmacol. Exp. Ther. 1971, 179,652659.

14. Sergio, H.F.; Berenice, B.L.; Fernando, M.A.C. Central and peripheral anti analgesic action of aspirin-like drugs. J. PET. 1971, 177, 509-513.

15. Dobuisson, D.; Dennis, S.G. The formalin test: A quantitative study of the analgesic effects of morphine, meperidine, and brain stem stimulation in rats and cats. Pain 1977, 4, 161-174.

16. Wheeler-Aceto, H.; Cowan, A. Neurogenic and tissue mediated components of formalin-induced edema: evidence for supraspinal regulation, Agents Action. 1991, 34, 264-269.

17. Jeffrey, A.; Gudin, M.D. Expanding Our Understanding of Central Sensitization. Medscape Neurol. Neurosurg. 2004, 6, 1.

18. Sofowara, A. Medicinal Plants and Traditional Medicine in Africa; John Wiley and Sons, Ltd: New York, NY, USA, 1982.

19. Harborne, J.B. Phytochemical Methods; Chapman and Hall: London, UK, 1973; pp. 49-188.

20. Siddiqui, A.A.; Ali, M. Practical Pharmaceutical Chemistry, 1st ed.; CBS Publishers and Distributors: New Delhi, India, 1997; pp. 126-131.

21. OECD (Organization for Economic Cooperation and Development). OECD Guidelines for Testing of Chemicals 423: Acute Oral Toxicity-Acute Toxic Class Method, 1st Adoption; Organization for Economic Cooperation and Development: Paris, France, March 22, 1996.

Sample Availability: Samples of the compounds are available from the authors.

(C) 2010 by the authors; licensee Molecular Diversity Preservation International, Basel, Switzerland. This article is an open-access article distributed under the terms and conditions of the Creative Commons Attribution license (http://creativecommons.org/licenses/by/3.0/). 